\title{
México: retrospectiva y perspectiva gubernamental, 20|4-2020
}

\section{Gabriel Delgado Toral*}

El pasado viernes cinco de septiembre la Secretaría de Hacienda y Crédito Público (SHCP) a cargo del recién nombrado "Ministro de Finanzas del año 2014"1 Luis Videgaray Caso entregó el Paquete económico para 2015, el cual contenía la Iniciativa de Ley de Ingresos de la Federación, el Proyecto de Presupuesto de Egresos de la Federación y los Criterios Generales de Política Económica (CGPE). En este Paquete se "sintetizan" una serie de reformas que el gobierno de Enrique Peña Nieto, presidente de México, llevó a cabo durante los últimos meses. Tomando como base los datos y documentos oficiales, principalmente, el objetivo del siguiente artículo es analizar cómo cierra la economía mexicana el año 2014 y qué se espera en el paquete económico para los próximos seis años. Por último se harán algunos comentarios de este breve texto.

\section{Indicadores económicos al cierre de 2014}

Las estimaciones de crecimiento económico oficiales y de organismos nacionales e internacionales para el cierre del año son poco optimistas. De

1 Reconocimiento entregado por la revista Euromoney. El editor Clive Horword señaló que esa distinción "es un reflejo del efecto transformacional que el reciente programa de reformas estructurales tendrá sobre la economía mexicana". acuerdo con la Secretaría de Hacienda y Crédito Público (SHCP) el producto interno bruto (PIB) cerrará el año en $2.7 \%$. El Banco Mundial (BM), el Fondo Monetario Internacional (FMI) y la Organización para la Cooperación y Desarrollo Económico (OCDE) pronosticaron un crecimiento aún menor: 2.3 (en junio), 2.4 (en junio) y $2.2 \%$ (en mayo), respectivamente. Los analistas encuestados por el Banco de México (Banxico) (agosto), por un lado, y el Departamento de Estudios Económicos y Sociopolíticos (DEEs) de Banamex (julio-agosto), por el otro, también son pesimistas respecto al comportamiento del producto interno bruto (PIB) mexicano: 2.5 y $2.6 \%$ (véase Cuadro 1, Panel A).

Varios son los factores que afectaron los pronósticos de las instituciones antes mencionadas, aunque coinciden en dos de ellos: la menor producción de los yacimientos en la sonda de Campeche (Cantarell y Ku-Maloob-Zaap) es ya un problema latente para las finanzas públicas que han deteriorado (todavía más) los ingresos petroleros para los ejercicios fiscales en puerta; otro factor importante es la recuperación lenta de la economía estadounidense, de la cual México es altamente dependiente, y la cercana "normalización" de su política monetaria. Ante ese complicado panorama el subsecretario de Hacienda y Crédito Público

\footnotetext{
* Profesor de la Facultad de Economía, UNAM y alumno de la Maestría en Ciencias en Metodología de la Ciencia, CIECAS-IPN.
} 
Fernando Aportela Rodríguez afirmó que "el paquete económico se elaboró sobre la fortaleza de la economía y de las finanzas públicas, así como de los beneficios estimados de las reformas".

Otra perspectiva del comportamiento de la economía mexicana al cierre del año nos la da el marco macroeconómico. En una economía abierta se puede analizar la coherencia de las políticas mediante el equilibrio entre los sectores interno y externo con la llamada "ecuación de flujo de fondos". En esta ecuación contable la brecha del sector externo, es decir, el saldo de la balanza corriente [exportaciones (X) menos importaciones (M)] debe ser igual a la brecha del sector privado [entre ahorro (S) e inversión (I)] más la brecha del sector público [entre ingresos $(\mathrm{T})$ y gastos $(\mathrm{G})]$ (véase Ecuación 1). según el staff de la presidencia, con el Acuerdo de Certidumbre Tributaria al "mantener sin variaciones el régimen fiscal durante toda la administración"). Para 2014, de acuerdo con los datos de la SHCP, el saldo de la cuenta corriente será de $-1.9 \%$ y el balance fiscal de $-1.5 \%$, por lo tanto, el sector privado también debería estar operando con un déficit (véase Cuadro 1, Panel B).

\section{Perspectivas para 20I5-2020}

¿Y qué tan coherentes son las propuestas del paquete económico 2015, siguiendo con la ecuación de flujo de fondos? Para el corto plazo la SHCP proyectó un déficit en la cuenta corriente (del sector externo) de dos

$$
\begin{aligned}
\text { Sector externo }= & \text { Sector privado }+ \text { Sector público } \\
& (\mathrm{X}-\mathrm{M})=(\mathrm{S}-\mathrm{I})+(\mathrm{T}-\mathrm{G})
\end{aligned}
$$

El enfoque macroeconómico seguido por la administración de Peña Nieto en 2014 ya tomó en cuenta los impuestos que entraron en vigor a principios de año (alimentos con alto valor calórico y bebidas soborizadas, comida para mascotas, transporte foráneo, incrementos mensuales en el precio de la gasolina, entre otros), los cuales buscan mitigar la inevitable y clara reducción de los ingresos petroleros y así evitar una posible crisis presupuestal (que podría prevenirse, por ciento, mientras que el saldo del balance fiscal (del sector público) registrará un punto porcentual negativo, sin embargo "no propone nuevos impuestos, no propone aumentos a los existentes, ni disminuciones a los beneficios fiscales" (SHCP, 2014) como consecuencia de los menores ingresos petroleros -ya mencionados en la sección anterior. ${ }^{2}$ Eso quiere decir que el

$2 \mathrm{Y}$ sí afirma seguir con "el gasto en proyectos de alto impacto económico y social en beneficio de las familias mexicanas". 
Economía Informa núm. 388 septiembre - octubre • 2014 | " " " " " " " " " "

\section{Cuadro I}

Perspectivas de la economía mexicana, 2014-2015*

\begin{tabular}{l|c|r|r|r|}
$\begin{array}{l}\text { Panel A. Pronósticos de crecimiento } \\
\text {-como \%, variación real anual- }\end{array}$ & \multicolumn{3}{c|}{$\begin{array}{c}\text { Panel B. Marco macroeconómico } \\
\text {-como \%- }\end{array}$} \\
\hline & 2014 & & 2014 & 2015 \\
\hline SHCP & 2.7 & PIB (var. real anual) & 2.7 & 3.7 \\
\hline BM & 2.3 & inflación (dic.-dic.) & 3.9 & 3 \\
\hline FMI & 2.4 & cuenta corriente (\% del PIB) & -1.9 & -2 \\
\hline OCDE & 2.2 & balance fiscal (\% del PIB) & -1.5 & -1 \\
\hline $\begin{array}{l}\text { Encuesta de expectativas de } \\
\text { Banxico }\end{array}$ & 2.5 & tasa de interés & & \\
\hline DEES de Banamex & 2.6 & nominal promedio & 3 & 3.3 \\
\hline Fuente: elaboración propia. & & real acumulada & -0.8 & 0.3 \\
\hline
\end{tabular}

* Cifras estimadas.

sector privado debería tener un desempeño deficitario neto para que se llegue al equilibrio global de la propuesta gubernamental (véase Cuadro 1, Panel B y Cuadro 2).

De manera implícita se puede suponer que el desempeño del sector privado será el esperado aunque no con la magnitud deseada. La reforma energética aprobada recientemente permitirá a las empresas extranjeras invertir en el sector petrolero para 2015. En palabras oficiales: "la plataforma total de producción de crudo y gas en nuestro país puede provenir ya no sólo de Pemex sino de potenciales productores adicionales. El marco macroeconómico ya refleja esta distinta composición de la plataforma petrolera" (SHCP, 2014). Y el jefe de la Unidad de Planeación Económica de la Hacienda Pública Ernesto Revilla Soriano lo confirmó: “[en la propuesta] se mejora la composición del balance público porque privilegia el gasto en inversión [privada] sobre el gasto corriente".

En el mediano plazo se espera que como resultado de las llamadas "reformas del siglo xxI" el PIB crezca en torno a $5 \%$, mientras que el saldo de la cuenta corriente sea de $-2 \%$. Como en cada anuncio del banco central, se espera que la inflación converja a su blanco de 3\% (aunque la mayoría del tiempo está por arriba de ese objetivo, incluso, algunos meses, por arriba de su banda de variabilidad de más/ menos un punto porcentual). En este caso se espera que la tasa de interés nominal, los Cetes a 28 días, aumente gradualmente hasta 2020 -ha de de- 
cirse en este punto que la SHCP toma como referencia esta tasa siguiendo la tasa objetivo del banco central; una buena respuesta de la autoridad monetaria sería con aumentos o disminuciones de la tasa de interés más que proporcionales a las variaciones alcistas o bajistas de la inflación (véase Cuadro 2).

\section{Comentarios finales}

No sólo México tendrá un crecimiento económico moderado, también los diversos organismos nacionales (oficiales) e internacionales modificaron a la baja las perspectivas para la economía mundial. Por ejemplo, el FMI pronosticó (en julio) un crecimiento para todos los países de $3.4 \%$ y de $1.8 \%$ para las economías avanzadas. Las economías emergentes, como la mexicana, deberán esperar el repunte de las economías de Estados Unidos y de la zona euro para que la economía global se pueda desplegar como se espera. En palabras de Videgaray "el reto [para la economía mexicana] es la implementación eficaz y a tiempo de[1] conjunto de reformas, y sin duda alguna, la reforma que marca[rá] el cambio más trascendente y más profundo de este ambicioso paquete de cambios es la Reforma Energética".

El bajo crecimiento de la actividad económica, reflejado en las expectativas de las instituciones nacionales e internacionales, es ya algo que caracterizará al gobierno de Peña Nieto: 4\% "heredado" de Felipe Calderón en 2012, 1.1\% en 2013 y, ahora, 2.7\% (esperado) para 2014. Debe destacarse, también, que el cambio de metodología para la medición del balance fiscal mexicano - "derivado de los cambios asociados a la reforma energética, no considerará para la meta de balance un 2.5 por ciento del PIB asociado a la inversión de las Empresas Productivas del Estado (Pemex y CFE)" y los

\section{Cuadro 2}

Marco macroeconómico, 2015-2020*

\begin{tabular}{|c|c|c|c|c|c|c|}
\hline & 2015 & 2016 & 2017 & 2018 & 2019 & 2020 \\
\hline PIB (var. real anual) & 3.7 & 4.9 & 5.2 & 5.2 & 5.2 & 5.2 \\
\hline inflación (dic-dic.) & 3 & 3 & 3 & 3 & 3 & 3 \\
\hline cuenta corriente ( $\%$ del PIB) & -2 & -2 & -2.1 & -2.1 & -2.1 & -2 \\
\hline \multicolumn{7}{|l|}{ tasa de interés } \\
\hline nominal promedio & 3.3 & 3.9 & 4.5 & 5 & 5.5 & 5.9 \\
\hline real acumulada & 0.3 & 0.9 & 1.6 & 2.1 & 2.6 & 3 \\
\hline
\end{tabular}

* Cifras estimadas. Fuente: tomado de sHCP, 2014. 
"proyectos de inversión con alto impacto social o con fuentes de ingresos propios" (SHCP, 2014)- pondría en entredicho el equilibrio global de las políticas que la SHCP expone para los años venideros ya que la magnitud del déficit privado podría ser mucho mayor de lo esperado.

\section{Bibliografía}

Secretaría de Hacienda y Crédito Público (SHCP) (2014), "Criterios Generales de Política Económica para la Iniciativa de Ley de Ingresos y el Proyecto de Presupuesto de Egresos de la Federación Correspondientes al Ejercicio Fiscal 2015”, septiembre, México.

Diario El Economista (2014), diversas notas, varias fechas.

Diario El Financiero (2014), diversas notas, varias fechas.

Diario El Universal (2014), diversas notas, varias fechas.

Diario Excélsior (2014), diversas notas, varias fechas.

Diario La razón (2014), diversas notas, varias fechas.

Diario Reforma (2014), diversas notas, varias fechas. 